\title{
Identificação laboratorial dos patógenos oculares mais freqüentes e sua suscetibilidade in vitro aos agentes antimicrobianos
}

\author{
Laboratory identification of the most frequent ocular pathogens and their in vitro \\ sensitivity toantibiotics
}

\author{
Eliane Uesugui ${ }^{1}$ \\ Marcela Colussi Cypel-Gomes ${ }^{2}$ \\ Denise Atique ${ }^{3}$ \\ Dario Grechi Goulart ${ }^{4}$ \\ Fabiana Rega Gallucci ${ }^{5}$ \\ Maria Cristina Nishiwaki-Dantas ${ }^{6}$ \\ Paulo Elias Correa Dantas ${ }^{7}$
}

Trabalho realizado na Santa Casa de São Paulo. Setor de Córnea e Moléstias Externas Oculares e Laboratório de Microbiologia.

${ }^{1}$ Assistente do Setor de Córnea e Moléstias Externas do Departamento de Oftalmologia da Santa Casa de São Paulo.

${ }^{2}$ Médica do curso de Aperfeiçoamento do Pronto-Socorro do Departamento de Oftalmologia da Santa Casa de São Paulo.

${ }^{3}$ Assistente do Setor de Córnea e Moléstias Externas do Departamento de Oftalmologia da Santa Casa de São Paulo e Pós-graduanda, nível doutorado pela Universidade Federal de São Paulo - UNIFESP/EPM.

${ }^{4}$ Assistente do Setor de Retina e Vítreo do Departamento de Oftalmologia da Santa Casa de São Paulo.

${ }^{5}$ Residente do segundo ano do Departamento de Oftalmologia da Santa Casa de São Paulo.

${ }^{6}$ Chefe do Setor de Córnea e Moléstias Externas Oculares do Departamento de Oftalmologia da Santa Casa de São Paulo e Pós-graduanda, nível doutorado pela Universidade Federal de São Paulo - UNIFESP/EPM.

Assistente do Setor de Córnea e Moléstias Externas do Departamento de Oftalmologia da Santa Casa de São Paulo e Doutor em Medicina pela Universidade de São Paulo.

Endereço para correspondência: R. Professora Ruth Fonseca, 156 - Jundiaí (SP) CEP 13208-501.

E-mail:dggoulart@uol.com.br/deatique@uol.com.br

\section{RESUMO}

Objetivo: Estabelecer os agentes mais comumente isolados nas ceratites, conjuntivites e endoftalmites no Laboratório de Microbiologia da Santa Casa de Misericórdia de São Paulo, assim como determinar o perfil de sensibilidade destes agentes aos antibióticos. Métodos: Realizamos estudo retrospectivo analisando todos os prontuários oftalmológicos do banco de dados do Laboratório de Microbiologia da Santa Casa de São Paulo. Foram coletados os dados de todos os pacientes submetidos à colheita de material ocular nos últimos 5 anos (1994-1999). Selecionamos para o estudo apenas os pacientes com diagnóstico clínico de conjuntivite, ceratite e endoftalmite. Os respectivos antibiogramas foram realizados e somente dados de antibiótico com aplicação em oftalmologia foram analisados. Resultados: Dos 568 casos pesquisados, foram encontrados 282 casos de ceratite bacteriana (49,6\%), 214 de conjuntivites $(37,7 \%), 72$ de endoftalmites (12,7\%). Obtivemos cultura negativa em 333 casos $(58,9 \%)$. O agente mais freqüentemente isolado foi $S$. aureus ( 73 casos; $31,0 \%$ ). Nas conjuntivites, o segundo agente mais freqüente foi Candida sp $(6,6 \%)$ e $38,3 \%$ das culturas foram negativas. Nas ceratites, Pseudomonas aeruginosa apresentou 3,9\% de positividade. Nas endoftalmites, nas quais houve apenas $32 \%$ de positividade, o segundo agente mais freqüente foi o $S$. pneumoniae (4,2\%). Conclusão: Culturas negativas foram achado mais freqüente. Quando nos deparamos com uma infecção ocular, as chances de o causador ser $S$. aureus são muito grandes, portanto antes mesmo de se obter o resultado da cultura, tratamento que inclua $S$. aureus pode ser indicado.

Descritores: Infecções oculares/microbiologia; Testes de sensibilidade microbiana Conjuntivite bacteriana/microbiologia; Ceratite/microbiologia; Endoftalmite/microbiologia; Resistência microbiana a drogas

\section{INTRODUÇÃO}

A superfície ocular é colonizada por flora bacteriana que contribui com a modulação de sua defesa, associada a fatores humorais próprios da superfície ocular, inibindo o aparecimento de microorganismos patogênicos.

Com a mudança das condições normais da superfície ocular, os microorganismos, com seus fatores de virulência, ficam mais resistentes às defesas naturais e aumentam sua capacidade infecciosa. Para que a infecção ocular se instale é necessário aderência, penetração, invasão, persistência e replicação do microorganismo, independentemente dos mecanismos de de- 
fesa existentes. A capacidade de invasão microbiana decorre da capacidade de produção de exotoxinas, proteases e endotoxinas que destroem células e tecidos oculares ${ }^{(1)}$.

Algumas bactérias, no entanto, têm capacidade de penetrar o epitélio íntegro, como: $N$. gonorrhoeae, $N$. meningitidis, Corynebacterium diphtheriae, H. influenzae tipo III, Listeria monocytogenes e Shigella sonnei ${ }^{(1)}$.

O mais completo estudo sobre a flora ocular normal foi feito com mais de 10000 culturas da flora de pacientes normais. $S$. epidermidis, $S$. aureus e difterióides foram isolados na grande maioria dos pacientes, concluindo-se, a partir disso, que estes grupos de bactérias fazem parte da flora ocular normal ${ }^{(2)}$.

Antes do nascimento, a conjuntiva e as pálpebras são estéreis, pois o saco amniótico não está roto. A flora bacteriana é adquirida durante a passagem pelo canal de parto. A colonização do olho é retardada pela aplicação tópica de nitrato de prata ou antibiótico tópico para profilaxia da gonorréia e infecção por Chlamydia trachomatis. Após o nascimento, pessoas sadias de todas as idades apresentam aproximadamente a mesma característica quanto à população bacteriana ${ }^{(3)}$.

As conjuntivites, ceratites e endoftalmites podem ameaçar a integridade do olho e produzir significativa destruição tecidual $^{(2)}$. São problemas que necessitam de diagnóstico e terapia apropriada e precoce para melhorar seu prognóstico, principalmente no caso das ceratites e endoftalmites. Conhecimento do agente causador, do processo e progressão da doença, bem como estabelecimento de tratamento coerente e eficaz influenciam sobremaneira sua evolução e prognóstico ${ }^{(4)}$.

Os microorganismos mais freqüentemente encontrados na córnea acometida por doença bacteriana são, em ordem de freqüência: Pseudomonas aeruginosa, Streptococcus pneumoniae, Moraxella sp, Streptococcus $\beta$ hemolítico e Klebsiella pneumoniae ${ }^{(5)}$. Em outros estudos, os dados são diferentes: $S$. epidermidis $(47,4 \%)$, P. aeruginosa $(21,1 \%)$ e $S$. aureus $(17,8 \%)$ como os mais freqüentes ${ }^{(6)}$. Para as conjuntivites, os agentes mais freqüentes são $S$. epidermidis (46 cepas), S. aureus (33 cepas), S. pneumoniae (6 cepas), E. coli (5 cepas), Streptococcus sp (3 cepas), H. influenzae (3 cepas), Enterobacter sp (2 cepas), Pseudomonas sp (1 cepa), Alcaligenes sp (1 cepa), Diplococcus gram positivos (1 cepa), $N$. gonorrhoeae (1 cepa), P. mirabilis (1 cepa), S. viridans (2 cepas) e Haemophilus sp (1 cepa) ${ }^{(7)}$. Outros autores chegaram à conclusão de que os mais freqüentes são: $S$. pneumoniae, $S$. aureus, $H$. influenzae e $S$. coagulase negativo ${ }^{(1)}$.

Nas endoftalmites, os agentes mais freqüentes, em ordem decrescente, são: S. aureus, Pseudomonas sp, S. pneumoniae, Proteus sp, S. epidermidis, Haemophilus sp, Penicillium sp, Bacillus sp, Enterobacter, Candida sp e Fusarium sp ${ }^{(8)}$. Em outro estudo, constatou-se que os mais freqüentes foram, em ordem decrescente: $S$. aureus, S. epidermidis, P. aeruginosa, S. viridans, E. coli, S. $\beta$ hemolítico, E. cloaceae, S. pneumoniae, P. mirabilis, B. subtillis, Corynebacterium sp, Streptococcus sp e fungos ${ }^{(9)}$.

Este trabalho tem por objetivo estabelecer quais os pató- genos mais comumente isolados no Laboratório de Microbiologia da Santa Casa de São Paulo, bem como o perfil de sensibilidade aos antibióticos destes patógenos.

\section{MÉTODOS}

Analisamos todos os prontuários oftalmológicos $(\mathrm{n}=785)$ do banco de dados do Laboratório de Microbiologia da Santa Casa de São Paulo no período de janeiro de 1994 a outubro de 1999.

O método de coleta do material a ser examinado variou de acordo com o diagnóstico clínico. Nas suspeitas de conjuntivites, após anestesia tópica com proparacaína $0,5 \%$, foram utilizadas hastes de algodão flexíveis umedecidas em solução salina estéril, friccionadas na conjuntiva tarsal e fundo-desaco para cada olho. O material obtido era espalhado na porção superior da placa (ágar sangue, ágar chocolate, ágar manitol, tioglicolato, Lowestein-Jensen e McCoy, de acordo com a suspeita clínica levantada). As placas eram colocadas em incubadoras, sempre disponíveis.

Nas suspeitas clínicas de ceratite, os raspados foram feitos com auxílio de alça de platina (espátula de Kimura) flambada na chama de lamparina e esfriada em solução estéril. O primeiro raspado era rotineiramente destinado às lâminas para bacterioscopia citológica, coradas por Gram e Giemsa para análise imediata. A seguir era colhido material para cultura, semeando-o nas placas de ágar-sangue, chocolate e Sabouraud. Quando se suspeitava de algum agente que necessitasse de meio específico para seu crescimento, este era utilizado adequadamente. Para microorganismos anaeróbios foi usado meio de tioglicolato. Antes da coleta, o material necrótico era desprezado e as amostras colhidas das bordas e da região profunda da lesão. O procedimento era feito à lâmpada de fenda ou microscópio, com auxílio de blefarostato.

Nas suspeitas de endoftalmites, o material para cultura era colhido por meio de punção vítrea para biópsia, que era realizada com o olho previamente anestesiado com proximetacaína. A punção era feita via pars plana (a $4 \mathrm{~mm}$ do limbo) e entre a inserção dos músculos retos. Agulha montada em seringa era introduzida na conjuntiva e esclera até localizar uma bolsa de vítreo fluido, quando então eram aspirados de 0,2 a $0,5 \mathrm{ml}$ de vítreo. A inoculação era feita em meios de ágar-sangue, chocolate e Sabouraud rotineiramente, e procedia-se também a bacterioscopia com coloração por Gram e Giemsa para análise imediata $^{(10)}$.

Obtivemos 785 análises de material das mais variadas áreas do globo ocular com suspeitas de conjuntivite, ceratite, endoftalmite, dacriocistite e culturas de lentes-de-contato. Desprezamos os casos que apresentavam diagnóstico diferente dos de ceratite, conjuntivite ou endoftalmite, de modo que a amostra final foi de 568 casos.

Seus respectivos antibiogramas foram feitos através do método de difusão em discos. O teste de sensibilidade utilizado foi feito seguindo-se a padronização NCCLS da escala de Mc Farland (escala 0.5) (2). Utilizou-se o TSB, meio líquido 
próprio para crescer e multiplicar as bactérias. Molhou-se o swab no meio de TSB com o inóculo bacteriano e semeou-se na placa de Müller-Hinton (MH), na espessura de $150 \mathrm{~mm}$ e três posições, passando o swab em três sentidos, do começo ao fim da placa de MH. Em seguida, colocou-se os discos, contendo uma concentração conhecida do agente antimicrobiano, na placa de $\mathrm{MH}$ recém-inoculada. Começou-se, então, imediatamente a difundir-se e estabelecer gradiente de concentração ao redor do disco de papel filtro. Após a incubação de 24 horas na estufa de 37 graus Celsius foi feita a leitura dos halos dos antimicrobianos.

Somente dados de antibióticos com aplicação em oftalmologia foram analisados, porém respeitou-se a padronização do Laboratório de Microbiologia da Santa Casa de São Paulo. Para microorganismos Gram-negativos, os antibióticos testados foram: cefazolina, cefalotina, gentamicina, amicacina, cefotaxima, ceftriaxona, ciprofloxacina, levofloxacina, cloranfenicol, tetraciclina, tobramicina, ofloxacina e sulfonamidas. Já no caso de microorganismos Gram-positivos, o antibiograma testou: penicilina, oxacilina, eritromicina, vancomicina, cloranfenicol, ciprofloxacina, gentamicina, tetraciclina e sulfonamidas. Para P. aeruginosa, testou-se ceftazidima, gentamicina, amicacina, ciprofloxacina, tobramicina, cloranfenicol e ofloxacina.

Os dados foram tabulados em planilha eletrônica (Excel, Microsoft) e analisados estatisticamente.

\section{RESULTADOS}

Dos 568 casos pesquisados, foram encontrados, de acordo com o local de ordem e freqüência, 282 casos de ceratite bacteriana (49,6\% da amostra), seguida de 214 casos de conjuntivite dos mais variados tipos (como neonatal, bacteriana, alérgica etc), representando $37,3 \%$ de toda amostra, e, em terceiro lugar em ordem de freqüência, foram os casos de endoftalmite com 72 casos englobando cultura de humor aquoso e vítreo, resultando em $12,7 \%$ dos casos.

Os agentes foram separados de acordo com os diagnósticos, em ordem de freqüência na Tabela 1.

Por meio da análise dos antibiogramas dos agentes patogênicos encontrados verificamos os seguintes antibióticos mais sensíveis às respectivas bactérias.

Foram selecionados os antibióticos mais comumente encontrados e de acesso mais fácil aos pacientes. Foram eliminados antibióticos como imipenem, ácido nalidíxico, aztreonam, meropenem, entre outros, pois não são usados na prática oftalmológica.

\section{DISCUSSÃO}

Para diminuir o tempo, o custo de tratamento, os riscos de complicações e as seqüelas numa infecção ocular, é muito importante isolar o agente causador, porém nem sempre isso é possível, como demonstram claramente $58,9 \%$ das culturas com resultado negativo.

\begin{tabular}{|c|c|c|}
\hline Ceratite bacteriana & $\mathbf{N}$ & $\%$ \\
\hline Negativo $48 \mathrm{~h}$ & 202 & 71,7 \\
\hline S.aureus & 20 & 7,0 \\
\hline$P$. aeruginosa & 11 & 3,9 \\
\hline S. epidermidis & 6 & 2,2 \\
\hline Streptococcus pneumoniae & 7 & 2,5 \\
\hline K. pneumoniae & 2 & 0,7 \\
\hline Outros & 34 & 12,0 \\
\hline Total & 282 & 100,0 \\
\hline \multicolumn{3}{|l|}{ Conjuntivites } \\
\hline Negativo $48 \mathrm{~h}$ & 82 & 38,3 \\
\hline S. aureus & 49 & 22,9 \\
\hline Candida sp & 14 & 6,6 \\
\hline S. epidermidis & 11 & 5,2 \\
\hline$P$. aeruginosa & 5 & 2,4 \\
\hline K. pneumoniae & 5 & 2,4 \\
\hline Outros & 48 & 22,5 \\
\hline Total & 214 & 100,0 \\
\hline \multicolumn{3}{|l|}{ Endoftalmites } \\
\hline Negativo 48h & 49 & 68,0 \\
\hline S. aureus & 4 & 5,5 \\
\hline S. epidermidis & 2 & 2,8 \\
\hline S. pneumoniae & 3 & 4,2 \\
\hline Candida sp & 1 & 1,4 \\
\hline Outros & 13 & 18,0 \\
\hline Total & 72 & 100,0 \\
\hline \multicolumn{3}{|c|}{$\begin{array}{l}\text { Fonte: Laboratório de Microbiologia do Hospital da Santa Casa de São Paulo, } \\
\text { de } 1994 \text { a } 1999\end{array}$} \\
\hline
\end{tabular}

\begin{tabular}{|c|c|}
\hline \multicolumn{2}{|c|}{$\begin{array}{l}\text { Tabela 2. Susceptibilidade antimicrobiana in vitro dos agentes } \\
\text { isolados no Laboratório de Microbiologia da Santa Casa de } \\
\text { Misericórdia de São Paulo, no período de } 1994 \text { a } 1999\end{array}$} \\
\hline Agente & Antibiótico \\
\hline Staphylococcus aureus & $\begin{array}{l}\text { Vancomicina }(60)^{*} \text {, oxacilina }(46)^{*} \text {, } \\
\text { ciprofloxacina }(39)^{*}\end{array}$ \\
\hline Staphylococcus epidermidis & $\begin{array}{l}\text { Vancomicina }(18)^{\star} \text {, ciprofloxacina }(13)^{*} \\
\text { oxacilina }(13)^{\star}\end{array}$ \\
\hline Pseudomonas aeruginosa & $\begin{array}{l}\text { Ceftazidime }(13)^{*} \text {, tobramicina }(13)^{*} \\
\text { gentamicina }(12)^{*} \text {, ciprofloxacina }(12)^{*}\end{array}$ \\
\hline Klebsiella pneumoniae & $\begin{array}{l}\text { Ceftazidime }(8)^{*}, \text { tobramicina }(8)^{*} \\
\text { amicacina }(8)^{*}, \text { cefoxitina }(7)^{*}\end{array}$ \\
\hline Streptococcus pneumoniae & $\begin{array}{l}\text { Tetraciclina }(9)^{\star}, \text { vancomicina }(8)^{\star} \\
\text { cloranfenicol }(8)^{\star}, \text { ofloxacina }(8)^{*} \\
\text { penicilina }(8)^{*} \text {, eritromicina }(8)^{*}\end{array}$ \\
\hline \multicolumn{2}{|c|}{$\begin{array}{l}\text { ( )*-Número de casos onde houve sensibilidade do referido agente ao antibiótico } \\
\text { citado }\end{array}$} \\
\hline
\end{tabular}

Os resultados descritos na literatura são variados. Alguns estudos $^{(11)}$ encontraram $42,7 \%$ de positividade em culturas de material ocular, enquanto outros ${ }^{(6)}$ encontraram $47,1 \%$. Alguns autores ${ }^{(9)}$ referem $83,3 \%$ de positividade em culturas para suspeita diagnóstica de endoftalmite e outros ${ }^{(7)}$ tiveram, em sua amostra, $91,2 \%$ de positividade nas culturas para conjuntivites.

Nossos valores de positividade $(41,1 \%)$ devem ser discuti- 
dos e questionados, com a finalidade de melhorar os índices de positividade. Deve-se ter em mente que determinados fatores podem resultar em culturas negativas, tais como:

- Amostra de material ocular pequena;

- Cultivo em meios inadequados (ágar gelado ou com prazo de validade vencido);

- Transporte e armazenagem inadequados;

- Temperatura inadequada de incubação dos meios;

- Uso de colírios anestésicos com preservantes, que têm ação antibactericida, diminuindo a amostra dos patógenos ${ }^{(12)}$.

Quanto aos agentes mais freqüentemente isolados nas culturas para conjuntivites, nosso estudo teve o $S$. aureus $(22,9 \%)$ como o microorganismo mais freqüente, seguido pela Candida sp (6,6\%), S. epidermidis (5,2\%), Pseudomonas aeruginosa $(2,4 \%)$ e Klebsiella sp $(2,4 \%)$. Esses resultados diferem daqueles encontrados em outros estudos ${ }^{(7)}$, onde $S$. epidermidis foi o mais freqüente, com $37,9 \%$ dos casos, seguido pelo $S$. aureus, com 25,2\%. P. aeruginosa foi encontrado em $0,9 \%$ e não houve infecção por Klebsiella sp.

Com relação as infecções corneais, nossos resultados, onde $S$. aureus foi isolado em 7,0\%, P. aeruginosa em 3,9\% e S. pneumoniae em $2,5 \%$, são semelhantes aos citados na literatura ${ }^{(1)}$.

Com relação às endoftalmites, embora nossa positividade tenha sido relativamente baixa (32\%), o $S$. aureus, com 5,5\% dos casos seguido pelo $S$. pneumoniae $(4,2 \%)$ e pelo $S$. epidermidis $(2,8 \%)$ não diferem muito dos resultados encontrados por outros autores ${ }^{(8-9)}$.

Nosso estudo teve como objetivo agilizar e direcionar o tratamento das infecções oculares mais comuns. Desta maneira, tratamento mais eficaz para determinada infecção ocular pode ser sugerido, proporcionando ao paciente melhores resultados evitando, assim, complicações e tratamentos mais agressivos, como transplante tectônico penetrante de córnea.

\section{ABSTRACT}

Purpose: To establish the most frequently isolated agents in keratitis, conjunctivitis and endophthalmitis by the Laboratory of Microbiology/Santa Casa of São Paulo, and to determine their antimicrobial sensitivity. Methods: A retrospective study including all ophthalmologic charts of the Laboratory of Microbiology/ Santa Casa of São Paulo was conducted. All ocular material collected during the last five years was analy- zed. We included in this study only patients whose diagnoses were conjunctivitis, keratitis and endophthalmitis. Susceptibility tests of drugs with ophthalmological application were analyzed. Results: In a total of 568 cases, we found 282 of bacterial keratitis (49.6\%), 214 of conjunctivitis (37.7\%) and 72 of endophthalmitis (12.7\%); three hundred thirty-three negative culture cases were found (58.9\%). S. aureus was the most frequently isolated agent $(\mathrm{n}=73 ; 31.0 \%)$. Conjunctivitis showed Candida sp in $6.6 \%$ of all cases, and $38.3 \%$ of the cultures were negative. When the diagnosis was keratitis, $P$. aeruginosa was positive in $3.9 \%$ and $71.6 \%$ of the cultures were negative. Endophthalmitis showed only $32 \%$ of positivity. Conclusion: Inconclusive cultures were the majority. Facing an ocular infection, there is a considerable chance to find $S$. aureus.

Keywords: Eye infections/microbiology; Microbial sensitivity tests/utilization; Conjuntivitis bacterial/microbiology; Keratitis/microbiology; Endophthalmitis/microbiology; Drug resistance/microbial

\section{REFERÊNCIAS}

1. Vieira LA, Lima ALH, Cunha M, Mascaro V. Conceitos básicos e clínicos de doenças externas e córnea. In: Lima ALH, Dantas MCN, Alves MR. Doenças externas oculares e córnea. Rio de Janeiro: Cultura Médica; 1999. p.6-9.

2. Locatcher-Chorazo D, Seegar BC. Microbiology of the eye: the bacterial flora of the healthy eye. St Louis: Mosby; 1972. p.13-5.

3. Crede CSF. The prevention of ocular inflammation in the newborn. Die Verhütung der Augenentzundung der Neugeborenen, Archiv fur Gynaekologie $1881 ; 17: 50$.

4. Smolin G Thoft RA. The cornea. 2nd ed. Massachusetts: Mosby; 1987. p.204-14.

5. Grayson, M. Enfermedades de la córnea. 2 ed. Buenos Aires: Editora Médica Panamericana;1985. p.48-50.

6. Levey SB, Katz HR, Abrams DA, Hirschbein MJ, Marsh MJ. The role of cultures in the management of ulcerative keratitis. Cornea 1997;16:383-6.

7. Alves MR, Oréfice F, Gonçalves Neto P, Vila MF. Norfloxacina a 0,3\% no tratamento das conjuntivites e blefaroconjuntivites agudas. Arq Bras Oftalmol 1991;54:206-12.

8. Chaib AR, Freitas D, Scarpi MJ, Guidugli T. Pesquisa laboratorial em endoftalmite. Arq Bras Oftalmol 1997;60:250-7.

9. Schirmbeck T, Romão E, Rodrigues MLV, Figueiredo JFC. Endoftalmite: análise de 58 casos. Arq Bras Oftalmol 2000;63:39-44.

10. Santos PM, Nishi M, Güntzel I, Lima ALH. Princípios básicos do diagnóstico das infecções oculares. In: Lima ALH, Melamed J, Calixto N. Terapêutica clínica ocular. São Paulo: Roca; 1995. p.331-5.

11. Wang AG, Wu CC, Liu JH. Bacterial corneal ulcer: a multivariate study. Ophthalmologica 1998;212:126-32.

12. Dantas PE, Uesugui E, Nishiwaki-Dantas MC, Mimica LJ. Antibacterial activity of anesthetic solutions and preservatives (an in vitro comparative study). Cornea 2000;19:353-4.

\title{
ABO ELETRÔNICO
}

\author{
Novo site
}

Acesso: http://www.abonet.com.br 